\title{
DNA aneuploidy in Crohn's disease and ulcerative colitis: results of a comparative flow cytometric study
}

\author{
R Porschen, U Robin, A Schumacher, S Schauseil, F Borchard, K J Hengels, G Strohmeyer
}

\begin{abstract}
DNA ploidy and S-phase fractions were assessed by flow cytometry in colonic biopsy specimens from 28 patients with ulcerative colitis and 51 with Crohn's disease. Whereas only diploid DNA histograms were found in Crohn's disease and control subjects, three patients with ulcerative colitis exhibited DNA aneuploidy. In one case, aneuploidy was associated with low grade dysplasia. S-phase fractions were higher in ulcerative colitis (mean (SD) $17.8(7 \cdot 7) \%$ ) than in Crohn's disease $(13 \cdot 1(4 \cdot 6) \%)$ or control subjects $(14 \cdot 2$ $(4 \cdot 6) \%)$, but did not correlate with either disease activity or duration in any group. In this study, aneuploidy was associated exclusively with ulcerative colitis, even in the absence of dysplasia. In view of the epidemiological differences in malignant colonic transformation between ulcerative colitis and Crohn's disease, this study suggests that flow cytometry may help to identify individuals with an increased cancer risk in ulcerative colitis.
\end{abstract}

The predisposition of patients with ulcerative colitis to develop colorectal cancer is well established, especially in those with extensive and long standing disease. ${ }^{1-6}$ Compared with the general population, a five- to eightfold increased cancer risk was observed in all ulcerative colitis patients, and this increased to 19 fold in those with total colitis. Patients with Crohn's disease also show an increased risk of developing colorectal cancer but the magnitude of the risk is not as high as in ulcerative colitis. ${ }^{27-13}$

The increased incidence of colonic cancer in patients with ulcerative colitis has prompted a search for clinical and histological variables that may predict the increased risk. Histopathological detection of dysplasia, defined as an unequivocal neoplastic change in the epithelium, has been used as a marker of malignant transformation. However, there are problems in the interpretation of dysplasia, particularly in the presence of severe inflammation. ${ }^{15}$ For the early detection of malignancy, additional methods would therefore be of great value.

Flow cytometry has been used to detect abnormal DNA stem lines in patients with ulcerative colitis. ${ }^{15-20}$ However, the biological significance of DNA aneuploidy for predicting cancer development in ulcerative colitis is still not yet defined. We therefore compared the prevalence of DNA aneuploidy in ulcerative colitis and Crohn's disease in order to see if it parallels the epidemiological difference in the colonic cancer risk between these two inflam- matory bowel diseases. Furthermore, we aimed to correlate results of DNA analysis with histological and clinical findings.

\section{Methods}

\section{PATIENTS}

Our flow cytometric study was prospectively carried out in three groups of patients. The control group comprised 20 patients (infectious colitis $(n=4)$, diverticulosis $(n=1)$, gastrocolic fistula $(n=1)$, irritable bowel syndrome $(n=14)$ ).

There were 28 patients with ulcerative colitis. They had a mean (SD) disease duration of $5 \cdot 4$ $(4 \cdot 7)$ years (range $0.3-16$ years). In four patients, the disease was limited to the rectum. Left sided colitis (no involvement proximal to the hepatic flexure) was present in 13 patients and pancolitis in 11 patients. Disease activity was assessed according to Descos et al, Edwards and Truelove, and Talstad and Gijone. ${ }^{21-23}$ Mean (SD) disease activity was 30 (17)\% (range 0-61\%).

Forty one patients with Crohn's disease and colonic involvement were studied (ileocolitis $(n=32)$, colitis $(n=9))$. In addition, patients with Crohn's ileitis $(n=8)$ or Crohn's disease in the stomach or duodenum $(n=2)$ were evaluated. The mean (SD) disease duration of this group was $7 \cdot 2(6 \cdot 2)$ years (range $0 \cdot 1-22$ years). The Crohn's disease activity index (CDAI) was mean (SD) 202 (98) (range 22-429).

Patients were examined once after giving written informed consent. The study was undertaken over 12 months and was approved by the human research review committee of the Heinrich-Heine-University.

\section{ENDOSCOPY AND HISTOLOGY}

During colonoscopy, biopsy specimens were taken from different locations in the colorectum (caecum, ascending colon, hepatic flexure, transverse colon, splenic flexure, descending colon, sigmoid, rectum). In two patients with ulcerative colitis, specimens were taken from proctocolectomy tissue. In five patients with ulcerative colitis (three with known proctitis or proctosigmoiditis and two with very severe colonic inflammation or toxic megacolon) and in three patients with Crohn's disease (one with ileosigmoidostomy and two with insufficient purgative preparation) only sigmoidoscopy was performed. Two biopsy specimens were taken at each level. The specimens were taken as close together as possible in order to facilitate comparison between histological and flow cytometric 
results. One specimen from each location was routinely fixed in formalin, embedded in paraffin, and stained with hematoxylin and eosin. Histological slides were reviewed by one experienced pathologist (FB) who did not know the results of the flow cytometric analysis. Slides were classified according to the method of Riddell et $\mathrm{al}^{14}$ as: no dysplasia, indefinite dysplasia, low grade dysplasia, or high grade dysplasia.

\section{FLOW CYTOMETRY}

The other biopsy specimen was frozen at $-80^{\circ} \mathrm{C}$ in a DMSO-citrate buffer until flow cytometric analysis. ${ }^{24}$ Before analysis the samples were rapidly thawed in a water bath to $37^{\circ} \mathrm{C}$. Specimens were gently ground in a $0.3 \mathrm{~mm}$ steel mesh with a small glass pestle. The resulting cell suspension was flushed with $100 \mu$ phosphate buffered saline (PBS) into a test tube. This procedure resulted in a cell suspension mainly containing whole or disrupted colonic crypts. Epithelial cell aggregates and single epithelial cells were observed to a lesser extent (Fig 1). Light microscopic examination showed that non-epithelial cells did not exceed $15 \%$. Paraffin sections prepared from the rest of the specimens remaining in the steel mesh after grinding showed that the stroma retained its normal appearance, whereas nearly all the crypts in normal and inflamed tissues were devoid of epithelial cell elements. No preferential selection of cells from the base or the surface of the colonic crypts was observed. These observations show that flow cytometric analysis of cells released from the biopsy specimens by this method was mainly restricted to the epithelial cell population.

Cell nuclei were isolated by a single step detergent technique ${ }^{25}$ and stained with propidium iodide. In order to minimise aggregates, the suspension was passed several times through a pipette during the incubation period. After addition of RNase $(1 \mathrm{mg} / \mathrm{ml}), 10000$ nuclei per specimen were subsequently analysed in an EPICS C flow cytometer. The coefficient of variation of the $\mathrm{Gl}$ full peak in all samples was $4.9 \%(1 \cdot 1 \%)$. Cell cycle parameters were calculated using a polynomial model (SFIT). ${ }^{26}$ Data were corrected for background if a significant amount of debris was present in the sample.

Individual S-phase fractions of all colonic

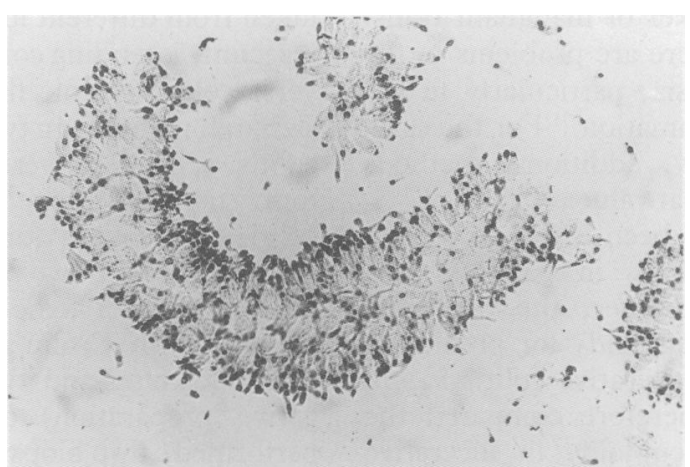

Figure 1: After grinding the biopsy specimens in a steel mesh the resulting cell suspension mainly consists of colonic crypts and epithelial cell aggregates.

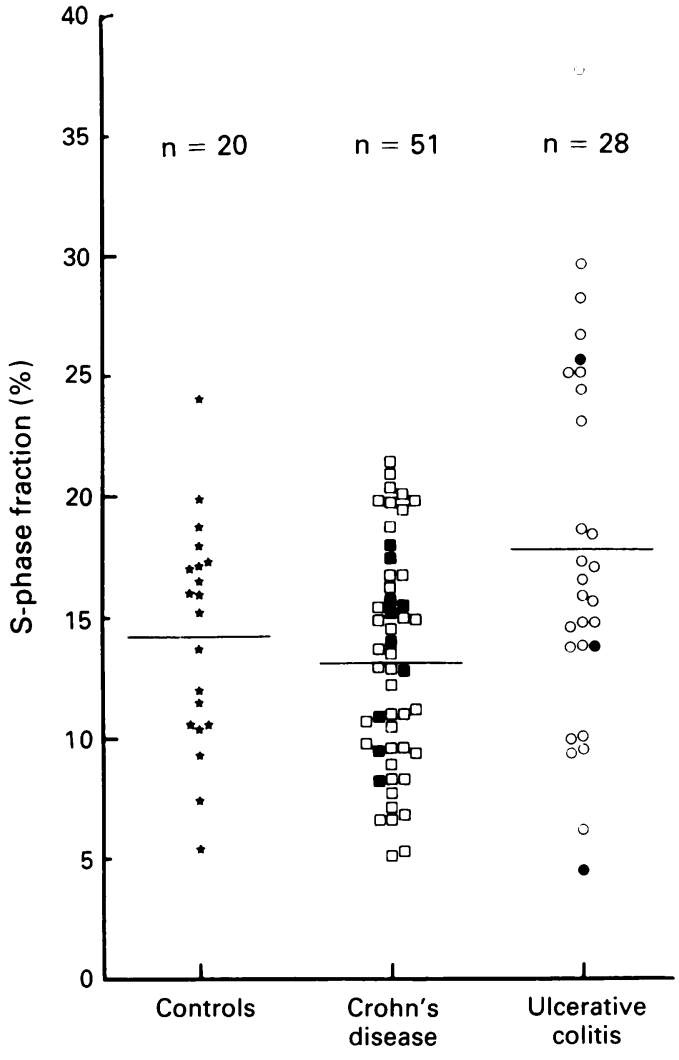

Figure 2: $S$-phase fractions in colonic biopsy specimens from control patients, patients with Crohn's disease (open squares: values in patients with colonic involvement; black squares: values in patients without colonic involvement) and those with ulcerative colitis (black dots: values in aneuploid patients) were calculated by means of a polynomial model. Each value represents the average of the $S$-phase fractions in all specimen taken from one patient. Mean $S$-phase fractions amounted to $14 \cdot 2(4 \cdot 6) \%$ in controls, $13 \cdot 1(4 \cdot 6) \%$ in Crohn's disease and $17 \cdot 8(7 \cdot 7) \%$ in ulcerative colitis.

biopsy specimens of each patient were pooled for statistical analysis. Comparison of sample means was done by Student's $t$ test or Kruskal-Wallis test statistic. Linear correlations were computed for comparisons of the S-phase percentages, disease duration, and disease activity. Samples with more than one peak in the histogram were judged as aneuploid. ${ }^{27}$ For DNA aneuploid samples a DNA index was calculated as the ratio of the abnormal G0/G1 mean peak channel number to the diploid G0/Gl mean peak channel number. DNA histograms were classified without knowledge of the histological results.

\section{Results}

CALCULATION OF S-PHASE FRACTIONS

S-phase fractions calculated by means of a polynomial model are depicted for control patients, patients with Crohn's disease, and those with ulcerative colitis in Figure 2. Values represent the mean of the S-phase fractions in all biopsy specimens taken from one patient. Because the $S$-phase fractions in Crohn's disease did not differ between patients with or without colonic involvement $(13.0(4.9) \% v 13.7(3.3) \%)$ these data were combined in Figure 2 to form a single group. The mean S-phase fraction in all patients with Crohn's disease was $13 \cdot 1(4 \cdot 6) \%$.

Mean values of pooled S-phase fractions in 


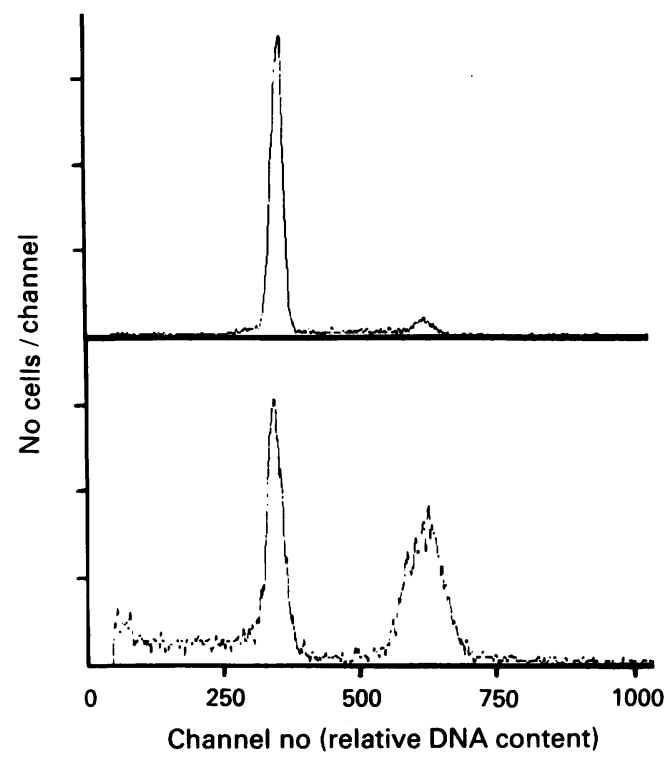

Figure 3: Diploid DNA histogram in a patient with Crohn's colitis (top). DNA histogram in a patient with ulcerative colitis showing a significant aneuploid peak with a DNA index of 1.9 (bottom)

controls and in patients with Crohn's colitis were nearly identical - $14 \cdot 2(4 \cdot 6) \% v 13 \cdot 0(4 \cdot 9) \%$ - and their distributions were overlapping. However, the mean S-phase fraction calculated in biopsy specimens from patients with ulcerative colitis increased to $17 \cdot 8(7 \cdot 7) \% \mathrm{p}<0.05)$. The means of these pooled $S$-phase values were nearly identical to the individual S-phase biopsy data in these three groups (controls: 13.9 (5.4)\%; Crohn's disease: $13 \cdot 3(5 \cdot 9) \%$; ulcerative colitis: $17 \cdot 5$ $(8 \cdot 4) \%)$. There was a wide scatter of S-phase fractions in ulcerative colitis ranging from $4.5 \%$ to $37 \cdot 7 \%$. In eight (29\%) patients with ulcerative colitis, but in none with Crohn's disease, mean S-phase fractions exceeded the upper limit seen in controls (Fig 2).

Neither in ulcerative colitis nor in Crohn's disease did a significant correlation between calculated disease activity and the S-phase fraction exist. In biopsy specimens showing highly active ulcerative colitis, S-phase fraction increased to $18.9(9 \cdot 4) \%$ compared with specimens showing histologically quiescent colitis (17.0 $(8 \cdot 3) \% ; p=N S)$. This insignificant increase in the S-phase fraction as a function of histological

Individual results of DNA aneuploidy, dysplasia, and clinical features in six patients with ulcerative colitis. Locations of biopsies are given in parentheses.

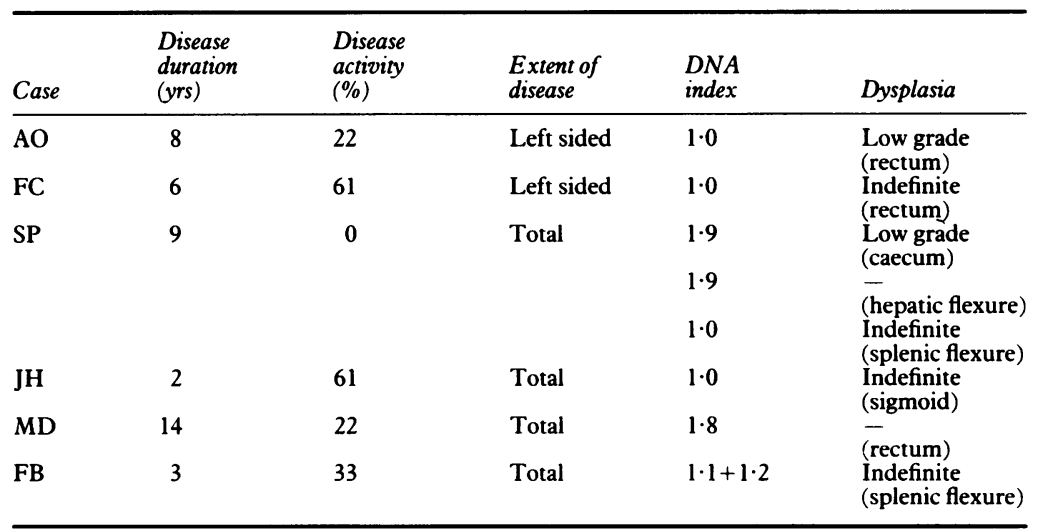

disease activity was also found in Crohn's disease $(15 \cdot 1(6 \cdot 0) \%$ v $13 \cdot 1(5 \cdot 6) \%)$.

Because the colonic cancer risk increases with the duration of ulcerative colitis, the impact of disease duration on the S-phase fraction was analysed. No statistically significant correlation could be shown between the duration of disease and the S-phase fraction in Crohn's disease or ulcerative colitis.

\section{DYSPLASIA AND DNA PLOIDY}

Five patients with ulcerative colitis showed either indefinite $(n=3)$ or low grade dysplasia $(n=2)$. Dysplastic changes were not present in biopsy specimens from controls or patients with Crohn's disease.

Only diploid DNA histograms were observed in control and Crohn's disease subjects (Fig 3). In contrast to these flow cytometric findings, three patients with ulcerative colitis (11\%) showed additional aneuploid DNA peaks (Fig 3). In two patients (patients SP and MD) a significant second peak was present in the tetraploid region with DNA indices of 1.9 and 1.8 , respectively (Table $\mathrm{I}$ ). In the third patient (patient FB) two additional aneuploid DNA stem lines with DNA indices of $1 \cdot 1$ and $1 \cdot 2$ were found in a biopsy specimen taken at the splenic flexure.

The Table summarises the results in six patients with ulcerative colitis in whom either dysplasia or DNA aneuploidy, or both were found. Disease duration in these patients ranged from 2 to 14 years. In most patients, total colitis was present. In patients $S P, M D$, and $F B, D N A$ aneuploidy could be shown by flow cytometry. DNA aneuploidy was not always accompanied by the simultaneous presence of dysplasia (patients SP and MD). Biopsy specimens classified as indefinite for dysplasia (in all cases probably negative) were often associated with a severe disease activity.

\section{Discussion}

The assessment of 'premalignancy' and increased cancer risk in inflammatory bowel disease is based on the histological finding of dysplasia, which can develop in ulcerative colitis $^{1+}$ and to a lesser extent in Crohn's disease. ${ }^{28}$ However, two problems become evident if dysplasia is used for risk assessment. Firstly, histological criteria are dependent on subjective judgement resulting in low interobserver agreement, especially in low grade dysplasia. ${ }^{15}$ The classification of dysplasia is impeded considerably by the presence of acute inflammation. Secondly, in inflammatory bowel disease neoplasms may develop without the simultaneous appearance of dysplasia at a distance from the colorectal cancer..$^{28}{ }^{29}$ The development of additional methods for the recognition of an increased cancer risk in patients with inflammatory bowel disease is therefore of great interest.

Hammarberg et $a l^{17}$ first reported the use of flow cytometry to detect DNA aneuploidy in biopsy specimens of ulcerative colitis. Demonstration of DNA aneuploidy in ulcerative colitis 
may precede the development of colon cancer. ${ }^{18}{ }^{19}$ In comparison with the classification of dysplasia, flow cytometry has the advantage in that interpretation of DNA histograms show a higher degree of interobserver agreement. ${ }^{\text {is }}$

Results concerning the association between DNA aneuploidy and dysplasia are discordant $^{15-171920}$ It has been hypothesized ${ }^{30}$ that aneuploidy in biopsy specimens interpreted as indefinite for dysplasia may predict future progression to definite dysplasia. The only case report of flow cytometry in Crohn's disease showed aneuploidy in a highly dysplastic mucosa. ${ }^{31}$ Aneuploid cell clones were detected in three patients with total colitis out of 28 patients with ulcerative colitis ( $11 \%$ for the whole group; $27 \%$ for the group with total colitis). These percentages are comparable with those in other studies. ${ }^{16171920}$ In patients SP and MD, near tetraploid cell clones were identified in inflamed mucosa without dysplastic changes. This observation confirms other flow cytometric studies in which the percentage of aneuploid histograms in non-dysplastic mucosa ranges from 2 to $33 \% .^{15-1720}$

The percentage of aneuploid subpopulations seems to increase with the duration of ulcerative colitis. On the other hand, DNA aberrations have been detected as early as four years after clinical symptoms have started. ${ }^{16} 17$ In patient FB, aneuploidy was found three years after disease onset in the proctocolectomy specimen. A significant correlation between the S-phase fraction and disease duration was not found in our study.

Flow cytometrically calculated S-phase fractions in control biopsy specimens agree with the labelling index of the human colonic mucosa $(12-18 \%)$ after in vivo injection of tritiated thymidine. ${ }^{32}$ The preparation method used in this study generated a cell suspension with a predominating proportion of epithelial cells. This explains the difference from other flow cytometric estimations of S-phase fractions which produced lower percentages. After the isolation of a pure epithelial cell suspension the mean proportion of colon cells in S-phase was determined to be $15-16 \%$ by flow cytometry. ${ }^{33}$

Our observation that cell proliferation is not increased in patients with Crohn's disease is confirmed by an autoradiographic investigation of Terpstra et al..$^{3+}$ On the other hand, tritiated thymidine studies have shown that the labelling index in ulcerative colitis is often increased above control values. ${ }^{35}{ }^{36} \mathrm{Kanemitsu}$ et $a l^{36}$ reported a mean labelling index of $20 \%$, with an upper limit of $37 \%$. In our ulcerative colitis group, S-phase fractions in eight patients exceeded the upper limit seen in controls. The significance of an increased S-phase fraction in ulcerative colitis is unclear. The proliferative compartment in ulcerative colitis is shifted to the luminal surface of the colonic crypts. ${ }^{37}$ This proliferative abnormality is interpreted as a marker of increased susceptibility to colonic cancer. ${ }^{32}{ }^{34}$

The biological significance of DNA aneuploidy and of changes in cell proliferation is still unclear. In our flow cytometric study, cell cycle phase fractions and the frequency of DNA aneuploidy were therefore compared in both forms of inflammatory bowel disease to see if they parallelled the epidemiological difference in colonic cancer risk. DNA aneuploidy was associated with ulcerative colitis, but not with Crohn's disease. In view of the epidemiological difference in malignant colonic transformation between ulcerative colitis and Crohn's disease, this study suggests that flow cytometry may help to identify individuals with an increased cancer risk in ulcerative colitis and that this method may become a valuable complement to histological examination in cancer surveillance programmes. The definitive importance of flow cytometry in inflammatory bowel diseases, however, has still to be assessed by prospective studies.

1 Broström O, Löfberg R, Nordenvall B, Öst A, Hellers G. The risk of colorectal cancer in ulcerative colitis. An epidemiologic study. Scand f Gastroenterol 1987; 22: 1193-9.

2 Ekbom A, Helmick C, Zack M, Adami HO. Ulcerative colitis and colorectal cancer. A population-based study. $N E n g l f$ Med 1990; 323: 1228-33.

3 Gilat T, Fireman Z, Grossman A, et al. Colorectal cancer in patients with ulcerative colitis. A population study in central Israel. Gastroenterology 1988; 94: 870-7.

4 Greenstein AJ, Sachar DB, Smith H, et al. Cancer in universal and left-sided colitis: factors determining risk. Gastroenterology 1979; 77: 290-4.

5 Gyde SN, Prior P, Allan RN, Stevens A, Jewell DP, Truelove $\mathrm{SC}$, et al. Colorectal cancer in ulcerative colitis: SC, et al. Colorectal cancer in ulcerative colitis: cohort study of prir

6 Katzka I, Brody RS, Morris E, Katz S. Assessment of colorectal cancer risk in patients with ulcerative colitis experience from a private practice. Gastroenterology 1983 85: 22-9.

7 Ekbom A, Helmick C, Zack M, Adami HO. Increased risk of large-bowel cancer in Crohn's disease with colonic involvement. Lancet 1990; 336: 357-9.

8 Fireman Z, Grossman A, Lilos $\mathrm{P}$, et al. Intestinal cancer in patients with Crohn's disease. A population study in central Israel. Scand $\mathcal{F}$ Gastroenterol 1989; 24: 346-50.

9 Greenstein AJ, Sachar DB, Smith H, Janowitz HD, Aufse AH. A comparison of cancer risk in Crohn's disease and AH. A comparison of cancer risk in Crohn
ulcerative colitis. Cancer 1981; 48: 2742-5.

10 Gyde SN, Prior P, Macartney JC, Thompson H, Waterhouse JAH, Allan RN. Malignancy in Crohn's disease. Gut 1980; 21: $1024-9$.

11 Korelitz BI. Carcinoma of the intestinal tract in Crohn' disease: results of a survey conducted by the national foundation for ileitis and colitis. Am $\mathcal{F}$ Gastroenterol 1983; 78 44-6.

12 Kvist $\mathrm{N}$, Jacobson $\mathrm{O}$, Norgaard $\mathrm{P}$, et al. Malignancy in Crohn's disease. Scand f Gastroenterol 1986; 21: 82-6.

13 Weedon DD, Shorter RG, Ilstrup DM, Huizenga KA, Taylor WF. Crohn's disease and cancer. N Engl f Med 1973; 289: 1099-103.

14 Riddeil RH, Goldmann H, Ransohoff DF, et al. Dysplasia in inflammatory bowel disease: standardized classification with provisional clinical applications. Hum Pathol 1983; 14: provisional

15 Melville DM, Jass JR, Shepherd NA, et al. Dysplasia and deoxyribonucleic acid aneuploidy in the assessment of precancerous changes in chronic ulcerative colitis. Observe variation and correlation. Gastroenterology 1988; 95: 668-75.

16 Fozard JBJ, Quirke P, Dixon MF, Giles GR, Bird CC. DNA aneuploidy in ulcerative colitis. Gut 1986; $27: 1414-8$.

17 Hammarberg G, Slezak P, Tribukait B. Early detection of malignancy in ulcerative colitis. A flow-cytometric DNA study. Cancer 1984; 53: 291-5.

18 Hammarberg C, Rubio C, Slezak P, Tribukait B, Öhman U. Flow cytometric DNA analysis as a means for early detection of malignancy in patients with chronic ulcerative colitis. Gut 1984; $25: 905-8$.

19 Löfberg R, Tribukait B, Öst A, Broström O, Reichard H Flow cytometric DNA analysis in longstanding ulcerative colitis: a method of prediction of dysplasia and carcinom colitis: a method of prediction of dysp

20 Rutegård J, Ahsgren L, Stenling R, Roos G. DNA Content in ulcerative colitis. Flow cytometric analysis in a patient series from a defined area. Dis Colon Rectum 1988; 31: 710-5.

21 Descos L, Andre F, Andre C, Gillon J, Landais P, Fermanian $\mathrm{J}$. Assessment of appropriate laboratory measurements to reflect the degree of activity of ulcerative colitis. Digestion 1983; 28: 148-52.

22 Edwards FC, Truelove SC. The course and prognosis of ulcerative colitis. I. Short-term prognosis. Gut 1964; 4 299-315.

23 Talstad I, Gijone E. The disease activity of ulcerative colitis and Crohn's disease. Scand f Gastroenterol 1976; 11: 403-8. Vindelov LL, Christensen IJ, Keiding N, Spang-Thomsen M, Nissen NI. Long-term storage of samples for flow cytometric DNA analysis. Cytometry 1982; 3: 317-22.

25 Thornthwaite JT, Sugarbaker EV, Temple WJ. Preparation of tissues for DNA flow cytometric analysis. Cytometry 1980; 1: 229-37. 
26 Dean PN. A simplified method of DNA distribution analysis. Cell Tissue Kinet 1980; 13: 299-308.

27 Hiddemann W, Schumann J, Andreeff M, et al. Convention on nomenclature for DNA cytometry. Cytometry 1984; 5 : $445-6$.

28 Korelitz BI, Lauwers GY, Sommers SC. Rectal mucosa dysplasia in Crohn's disease. Gut 1990; 31: 1382-6.

29 Ransohoff DF, Ridell RH, Levin B. Ulcerative colitis and colonic cancer. Problems in assessing the diagnostic usefulness of mucosal dysplasia. Dis Colon Rectum 1985; 28 : 383-8.

30 Haggitt RC, Rubin CE, Levine DS, Dean PJ, Rabinovitch PS Aneuploidy in ulcerative colitis biopsies that are histologically indefinite for dysplasia may predict future progression to definite dysplasia. Gastroenterology 1990; 98: A173.

31 McKinley MJ, Budman DR, Kahn E. High grade dysplasia in Crohn's colitis characterized by flow cytometry. $\mathcal{f}$ Clin Crohn's colitis characterized by flow cytometry. F Clin
Gastroenterol 1987; 9: 452-5.

32 Lipkin $M$ Proliferation and diseased gastrointestinal cells. In: Johnson LR, ed. Physio-
. logy of the gastrointestinal tract. 2nd ed. New York: Raven Press, 1987: 255-333.

33 Cheng H, Bjerknes M, Amar J. Methods for the determination of epithelial cell kinetic parameters of human colonic epithelium isolated from surgical and biopsy specimens. Gastroenterology 1984; 86: 78-85.

34 Terpstra OT, van Blankenstein M, Dees J, Eilers GAM. Abnormal pattern of cell proliferation in the entire colonic mucosa of patients with colon adenoma or cancer. Gastroenterology 1987; 92: 704-8.

35 Allan A, Bristol JB, Williamson RCN. Crypt cell production rate in ulcerative proctocolitis: differential increments in remission and relapse. Gut 1985; 26: 999-1003.

36 Kanemitsu T, Koike A, Yamamoto S. Study of the cell proliferation kinetics in ulcerative colitis, adenomatous polyps and cancer. Cancer 1985; 56: 1094-8.

37 Deschner EE, Winawer SJ, Katz S, Katzka I, Kahn E. Proliferative defects in ulcerative colitis patients. Cancer Invest 1983; 1: 41-7. 